\title{
Teaching Reform Method of Multivariate Statistic Analysis in Agricultural Colleges and Universities
}

\author{
YAN Tingyu \\ Department of Basic Courses, Beijing University of Agriculture, Beijing, 102206 \\ DU Xiaolin* \\ Beijing agricultural professional school office, Beijing, 102442 \\ Corresponding author
}

\begin{abstract}
In agricultural colleges, teaching method of multivariate statistical analysis can't copy the traditional teaching mode in science and engineering colleges. The author combined with years of teaching experience and the characteristics of agricultural science, discusses the teaching reform of multivariate statistical course in agricultural colleges, included optimize the course structure, reform the teaching content, reform teaching method, strengthen the experiment teaching, and reform assessment method.
\end{abstract}

KEYWORD: Multivariate statistical analysis; agricultural science; teaching method; experiment teaching

Multivariate statistic analysis is a mathematics subject studying the statistical law of multi-index random phenomenon and it is widely applied in the majors of agricultural colleges and universities. However, most of the students in agricultural universities and colleges are weak in mathematics and foundation of statistics and they do not adapt to the traditional teaching method of the mathematics courses for students of science and engineering. In combination with years' experience in teaching Multivariate Statistic Analysis and the characteristics of agricultural majors, the writer discusses the teaching reform on this course from the following aspects: teaching content, teaching method, experiment teaching and course assessment[1].

\section{OPTIMIZE THE COURSE STRUCTURE AND REFORM THE TEACHING CONTENT}

\subsection{Review the pre-knowledge}

The pre-knowledge of Multivariate Statistic Analysis includes calculus, linear algebra, probability theory and univariate statistical analysis. If Multivariate Statistic Analysis is directly taught, most of the students may have trouble in understanding the theories. Therefore, before learning the content of multivariate statistics, they should review the basic pre-knowledge. It is also necessary to systematically review the content of univariate variance analysis and univariate regression analysis before learning the multivariate variance analysis and multivariate regression analysis.

\subsection{Select textbook with targets}

Most of the textbooks of the science and engineering majors stress the systematic of mathematical knowledge, and the multivariate statistic analysis methods which are frequently used in the economy and finance cannot fully apply to the students of agricultural majors. Therefore, several textbooks should be referred to so as to select the multivariate statistic analysis methods that are often used in the agricultural majors, including the multivariate variance analysis and multivariate regression analysis which are not contained in most of the textbooks.

\subsection{Strengthen the statistical thinking and application and weaken the mathematical theories}

When teaching the specific multivariate statistical analysis methods, the teachers should lay stress on the thinking of the analysis methods and the problems they can solve, the steps and significance of method implementation and the result analysis, but weaken the theoretical derivation of methods and steps. For example, when teaching the hierarchical cluster analysis in cluster analysis, the definition modes of eight distances should be explained clearly, but about the specific calculation process, the relatively simple single linkage method may be selected to calculate and practice in details while other distance calculation with more complicated calculation process can be omitted. 


\section{STUDY ON THE REFORM ON TEACHING METHOD}

The teaching method of Multivariate Statistic Analysis is different from that of other courses because of the teaching time and the students' knowledge composition in agricultural colleges and universities. The teaching method can be reformed in the following aspects:

\subsection{Pay attention to the transition from univariate statistical analysis to multivariate statistical analysis}

When the Multivariate Statistic Analysis is studied, it is suggested that two classes should be used to review the pre-knowledge, especially the univariate statistical analysis. Correspondingly, the teachers should recommend reference books related to the pre-knowledge to the students. When giving lectures, the teachers should start from the knowledge of univariate statistical analysis and introduce the knowledge of multivariate statistical analysis through "expansion" and "extension".

\subsection{Pay attention to the comparison between similar multivariate statistical analysis methods}

During the lectures, when comparing the similar methods, the teachers should highlight their application conditions and distinguish the application situations of the methods. For example, the principal component analysis and factor analysis are two important dimensionality reduction methods, but the two methods are different in mathematical model, parameter uniqueness and factor choice.

\subsection{Pay attention to the organic combination of different multivariate statistical analysis methods}

When comparing different kinds of methods, the teachers should highlight their similarities and connections. For example, cluster analysis and discriminant analysis can both be used for classification. But, discriminant analysis needs to construct the classification model when the classification is known and it focuses on to which category the discriminant samples belong, while cluster analysis often determines the classification when the classification is unknown. [2]

\section{STRENGTHEN THE EXPERIMENT TEACHING}

Because the multivariate statistical analysis problems have mass data, the calculated amount is too large if the theoretical derivation is conducted, and the requirement for the students is high. Therefore, the experiment teaching should occupy an important position in this course. In the experiment teaching, the teachers should pay attention to the following aspects:

\subsection{Stress the verification operation.}

Apart from the specific operation of multivariate statistical analysis methods, the teachers should also stress the operation of preconditions of various methods. For example, when the multivariate analysis of variance and multivariate regression analysis are conducted, the normality and homogeneity of variance of data should be verified. [3]

\subsection{The calculation method should be as simple as possible.}

The students of agricultural majors do not have a high requirement for the data statistics, as long as they can solve the possible bottlenecks in the basic operations of various methods and the practical problems. When learning the software operation, the teachers should adopt as simple and intuitive methods as possible; if there are menu operations, programming operations should not be adopted.

\subsection{The example data collection should be in combination with the agricultural scientific research.}

In the experiment teaching, the examples the teacher adopts should use the agricultural professional data and background. Students can really feel the advantage of using multivariate statistical analysis methods to solve the agricultural professional problems. [4]

\subsection{Encourage the students to carry out studies in combination with their major.}

When learning this course, some students start the design and experiment of graduation dissertation, begin to touch the experimental data of the teachers and students in the scientific research teams, so the students should be encouraged to use the real scientific research data to conduct reasonable data analysis.

\section{REFORM ON THE COURSE ASSESSMENT METHOD}

The teaching method can affect the teaching content and the teaching content determines the assessment method. The traditional examination lays stress on the theory and calculation, so it is not suitable for the 
assessment of this course. Based on years' teaching practice, the writer suggests that this course should be assessed through computer operation, writing science and technology literature review and completing the course paper, and it focuses on knowing the ability of the students to solve problems with the multivariate statistic analysis methods.

Computer operation requires that the students should know the operation of statistical software well, be able to complete the application of the corresponding statistical methods for the given data and give correct explanation on the statistical result. The science and technology literature review can be conducted at the mid-term of this course. The students should be required to complete a review on the application of multivariate statistic analysis methods in the practical problems; and based on this, the students can deeply know the status and role of multivariate statistic analysis methods in the scientific research. The course paper requires the students should conduct a corresponding multivariate statistic analysis based on their own experiment data or the existing data in combination with their professional knowledge, and it encourages the students to systematically solve a practical problem of the major.

\section{CONCLUSION}

Multivariate Statistic Analysis is difficult to learn and widely applied, and the goal of teaching reform is "learning in order to practice". The teachers should continuously study, make improvement and perfect their own knowledge structure, and select the teaching mode and content which are more suitable for the students of agricultural majors. They should not only impart the correct statistical thinking to the students, but also should make the students have the ability to sort out data, analyze the data and solve the complicated problems. it can be believed that the knowledge of multivariate statistic analysis will be favored by more undergraduates and scientific and technical personnel and play a better role in the scientific research and management through continuous study and reform.

\section{ACKNOWLEDGEMENT}

Foundation: 2014 Beijing university of agriculture graduate reform and development of the project, Network teaching platform construction of multivariate statistical analysis and application I (2014YJS032)

\section{REFERENCES}

[1] Xiao Zhihong, Guo Mingyuee. The teaching reform and practice of graduate student multivariate statistical analysis, Higher Education of Sciences, 2009, 1(83):100-103

[2] Liu Yinping, An Liwei. Exploration and practice of teaching multivariate statistical analysis, Journal of Jilin Normal University (Natural Science Edition), 2011, 8(3):96-101

[3] Xie Fengchang, Li Qiang. Multivariate statistical analysis teaching discuss in agricultural colleges, China Agricultural Education, 2005, 6:28-29

[4] Tan Guanglian, Zhu Qiang. study and practice of teaching methods of multivariate statistical analysis, Mathematics teaching research , 2012, 11(31):53-61 